\title{
SHEN Cong-wen’s Aesthetic Modernity
}

\author{
CHEN Hua \\ Southwest University, Chongqing, China
}

\begin{abstract}
SHEN Cong-wen's aesthetic modernity is mainly reflected in three aspects. Firstly, SHEN Cong-wen negated the progressive linear time view of enlightening modernity, accepting modernity in an elastic time structure which consists of "the new" and "the old" as well as "constancy" and "change”. Then, SHEN Cong-wen carried forward the sensual life of human beings to make up for the abuse of reason in enlightening modernity, though he did not abandon the enlightenment reason. Moreover, in the Chinese context which lacked "reason" at that time, SHEN Cong-wen expected to bridge the gap between two cultures, namely, the culture of reason and the culture of sensibility. At last, the aesthetic view of redemption proposed by SHEN Cong-wen that "beauty lies in life" is essentially a kind of aesthetic utilitarianism which interweaves aesthetic independence and mind enlightenment.
\end{abstract}

Keywords: SHEN Cong-wen, aesthetic modernity, sensibility, aesthetic utilitarianism

\section{Introduction}

The theory of modernity is the "meta-discourse" dominating all fields in the 20th century. As the modern Chinese culture is just developing synchronously with the modernity of China's society and history, the modern Chinese culture has been under the influence caused by the discourse of modernity for a long time. The most notable manifestation is that the narrative of enlightening modernity has become the mainstream narrative pattern in Chinese literature. Moreover, the aesthetic modernity differentiates itself from the modernity per se, and it constantly reflects on the modernity in the meantime. Being different from the enlightening modernity which concerns material aspect and group consciousness of the society, the aesthetic modernity pays more attention to the individual sensual life. It undoubtedly enriches and develops modern Chinese literature on another dimension, which always lacks the sense of "personality" and "life". A clue of aesthetic modernity throughout can be found in SHEN Cong-wen's literary works and thoughts of literary theories with a detailed review of them.

\section{SHEN Cong-wen's Concept of Modernity}

The notion of modernity is first a kind of time consciousness or a kind of straight-forward and unrepeatable historical time consciousness, and it is a kind of notion of history which is completely opposite to the circular or mythic time frame (WANG, CHEN, \& WANG, 1994). This indicates that time consciousness is an important dimension to understand modernity. Being different from the endogenous and spontaneous Western modernity, Chinese modernity is implanted forcibly by Western powers and it is of obvious exogeneity and post-occurring characteristics. Moreover, because of the voluntary realization of dropping behind, most intellectuals in the 20th

CHEN Hua, Ph.D. candidate, School of Liberal Arts, Southwest University. 
century had a firm belief in the progressive linear-vector time view of modernity. When those intellectuals indiscriminately applied the time view enlightening modernity of social-level to literature, they fell into dilemmas of binary opposites such as new/old, modernity/tradition, West/East, and so on, stepping onto a theoretical path of single-linear modernity on which the former is superior to the latter. Just as KONG Fan-jin (2003) put it that,

from the literary revolution to the revolutionary literature, the realization of modernity of mainstream literature and the realization of historical modernity are taken in an integrated consideration, that is to say, the realization of modernity of both literature and history is the result obtained in inevitabilities of the law of historical evolution. (p. 99)

Nonetheless, the time view of enlightening modernity is different from that of aesthetic modernity.

From the social and historical perspective, modernity has inherently a strained relation of opposition and negation with traditional and ancient characteristics, whereas, from the aesthetic perspective, instead of a strained relation of opposition and negation, a relation of continuation lies more often between modernity and traditional ancient characteristics. This significantly shows the difference between social modernity and aesthetic modernity. (WEN, 2004, p. 6)

SHEN Cong-wen had a profound understanding on this paradoxical time view of modernity. On the one hand, SHEN Cong-wen had a clear time view of enlightening modernity in real life. In his essay "Responsibility”, for example, based on the time view of enlightening modernity, SHEN Cong-wen criticized fiercely the "party-cleansing movement" which happened during the Kuomintang-Communist splitting period and the “classics-reading movement” which aimed at restoring ancient ways. On the other hand, in his literary works implying personal emotions, SHEN Cong-wen queried the enlightening modernity which was dominated by the progressive linear-vector time view. In his novel The New and the Old which was also themed on the "party cleansing movement", SHEN Cong-wen ridiculed the notion of penalty that the modern execution of shooting was considered more advanced than the ancient execution of cutting heads. Just as some researchers pointed it out that, in SHEN Cong-wen's views,

the new is not completely opposite to the old, for it is more common to see that a new thing is mixed with old elements and that an old thing is provided with a new brand. Thus, it can be seen that history does not evolve in a linear way and that the situation of historical regression in which the new is inferior to the old often happens. (QIAN, 2001, p. 416)

This indicates that SHEN Cong-wen looked forward to modernity out of sense while lingered on pre-modernity out of sensibility. This envy-resentment complex of modernity forms a temporal polyphonic structure when it is reflected in literary works of SHEN Cong-wen. He once said he expected to "design his works to express the trend of past, present and future by focusing on combining constancy with change” (SHEN, 2002b, p. 7). Lamenting that people living in western parts of Hunan were out of the historical course of modernization, SHEN Cong-wen (2002c) once said:

They live with such loyalty and dignify and are responsible for their own fate,... In their life with love and hate as well as gain and loss, they are destined for crying, laughing, eating and drinking. They are more likely to feel the solemnity of the change of seasons at the summer or winter's coming than other people around the world. To them, history makes no sense. Nevertheless, their changeless and non-recorded history may bring about wordless sadness. (p. 253) 
On the other hand, SHEN Cong-wen (2002b) harbored to a certain extent resentment against negative values of modernity when people living in western Hunan were coerced into the course of modernization:

It superficially looks that all things and events have had great progress. If we look into those things and events closely enough, we will find that they are gradually in the trend of degradation. The most obvious thing is that the beauty of integrity, simplicity and kindness remained in the rural community is nearly about to disappear, and unfortunately it will be replaced by the reality-first and interests-first vulgar outlook on life which has been formed in the real society in recent two decades. Superstition in which ghosts and gods are respected and the mandate of heaven is revered has been destroyed by common sense. However, at the same time, the virtue of abandoning profits for righteousness and distinguishing the right from the wrong has also been lost. Although the term "modernization" has been popularized in western Hunan of China, in terms of concrete modern things, only a large number of luxuries are imported to embellish the urban civilization and first-rate cigarette and various canned goods are massively consumed by people at all levels. In terms of abstract things, there are only eight-part essays as official documents and sophisticated communication which are popular in political circles. (p. 3)

In order to keep the "constancy" characteristic of western Hunan, SHEN Cong-wen created a literary "Xiang $\mathrm{Xi}$ " (western parts of Hunan) with his dreams, memories, and imaginations to fight against the reality and to criticize the modern urban civilization. Enlightening modernity glorifies "the new" and "change” while SHEN Cong-wen indulged in "the old" and "constancy", and negated unified prospect of enlightening modernity on "progress".

\section{Bridging the Gap Between Reason and Sensibility}

In Western culture, enlightening modernity is the result of the Enlightenment Movement. The Enlightenment Movement broke shackles of religions and theologies in the Middle Ages, and it showed a prospect of world based on knowledge and reason after disenchanting the religious world. However, some new problems have been caused to the social development since the Enlightenment Movement due to the excessive reliance on knowledge and reason. Just as Schiller (1984) pointed it out that,

if reason has excessive expectations over human beings, and even deprives human beings of the means with which they exist with animality, so as to keep some kind of human nature (whose lack does not damage human beings' survival), then it's nothing but to take away the conditions on which human nature survives. (p. 41)

Modern civilization develops at the cost of suppressing the "emotional impulsion" (instinct) of human beings with instrumental reason. Therefore, Western countries have always tried to create an aesthetic Utopia since Rousseau called on returning to Nature, aiming to make up for the disintegration of human nature.

SHEN Cong-wen inherited the tradition of aesthetic modernity advocated by Nietzsche that sensual life was the priority. In his essay "My Studies”, he said:

Immaterialism and materialism as well as science and metaphysics intrude into my ideas and consciousnesses successively without my permission and their influences on me are therfore in a mess. Since the mode of thinking is in many ways, it is easier to combine the mode of thinking with personal emotions. Moreover, the mode of thinking is not Marx's new designs which are well organized and are made for the human society but some individual-centered segmented impressions or thoughts of the school of Gide and Nietzsche. (SHEN, 2002d, p. 362)

For this reason, SHEN Cong-wen was fond of such themes as promoting the sensibility of human beings and opposing constraints of knowledge and reason to life. 
In "After Raining”, Sigou enjoyed sexual pleasures with Dajie (an elder lassie) in a wild field on such a sunny day after raining. SHEN Cong-wen (2002a) could not help but exclaiming, "Fortunately, Sigou is illiterate, or otherwise, this pair of lovers should have been more unlikely to find out such funs in this good weather" (p. 276). His other works eulogizing this barbaric libido include "Picking Fernbrake”, “The Inn”, and "Cedar Seed”. Sex is the most primitive life instinct of human beings. Carrying forward the sensual desire and the subjectivity of human being, these works describing primitive and instinctive sexual activities are people-centered, for they challenge feudal ideas and the hypocritical modern civilization which consider sexual activities as nasty events in the name of morality.

Enlightening modernity upholds knowledge and reason, but SHEN Cong-wen (2002e) was doubtful to this point:

In terms of the material, human beings' progress is obvious. However, in terms of the reason, what is the difference between the people now alive and the people one thousand years ago? What progress has already been made? Answers to these questions are indeed doubtful. (p. 60)

In his novel "The Story of Meeting Again the Barbaric Man” (2002f), SHEN Cong-wen caustically ridiculed knowledge and reason by describing a barbaric man refusing to accept the modern education and escaping back to the place which was surrounded by high mountains and marshlands and suitable to his growth. SHEN Cong-wen's critical comments on the modern civilization are expressed more often in his novels themed on the urban civilization critique. According to SHEN Cong-wen, it is knowledge that makes the urban people become pathetic and hypocritical.

To SHEN Cong-wen, it is indubitable that the development of any culture has its advantages and disadvantages; "Xiangxi” is the symbol of nature and health and its primitive culture symbolizes ignorance. In “Cedar Seed” (2002g), SHEN Cong-wen spoke highly of the primitive and strong vitality of human beings while criticizing that human beings were never ready for the mercy from others or themselves. In "Xiaoxiao" (2002h), the heroine Xiaoxiao could not control her own destiny from beginning to end. People in "Xiangxi” live a primitive, authentic, and natural life, and therefore, they lack the enlightenment of reason. Their world of reason is always in an unawakened chaotic and dormant state, which is contradictory to the urban civilization advocating reason. It also made SHEN Cong-wen upset, for he was in the conflict and confrontation between two civilizations. He once said, "the cognition on both sides bring many troubles to me, and the conflict and the incompatible life make me separated from happiness forever” (SHEN, 2002i, p. 306). To him, the aim of criticizing modern civilization is not to call on returning to the barbarism and instinct. Similarly, the return of aesthetic modernity to sensibility does not mean it completely abandons reason. China was then confronted with domestic strife and foreign aggression, and reason was not as "too much" as in Western countries but obviously "insufficient”. SHEN Cong-wen spared no effort to describe the primitive sensibility of people in western Hunan in his works, for the purpose of rectifying the unbalances of human nature caused by the deformed development of reason in modern civilization. He also wanted to integrate the primitive, strong, and authentic vitality with beauty and kindness, leading the pursuit of truth to the pursuit of beauty and kindness as well as leading the pursuit of the natural state to the pursuit of the moral state, so as to complete the transition from the human nature to the divine nature. He finally hoped to unfasten the fast knot interweaving nature and culture due to the lopsided 
development of human society and use the integrated culture to reshape national characters of the Chinese nation, so as to realize the great rejuvenation of the Chinese nation, and to focus the eyes on the outlook of human beings.

\section{Aesthetic Utilitarianism and Aesthetic Redemption}

Pursuing literary and artistic independence and self-discipline is a distinct characteristic of aesthetic modernity. SHEN Cong-wen firmly insisted that the literature discipline should be independent, and he called on retaking "literature" as a department of "academic science".

The solemnity of academic science lies in the pursuit of genuine knowledge and the wide application of free criticism and exploration spirit, which is exactly the necessary condition for producing great literatures. Super-utility view of academic science has been recognized as one principle of academic progress in national education design, and it is beneficial to the national development. (SHEN, 2002j, p. 295)

SHEN Cong-wen made a severe criticism on the "almost-enough" phenomenon which was widely discussed in the literary world, and he held that the reason for the loss of artistic individuality is that writers had too close a relation with the era and they took literature as political and commercial tools and they did not attach importance to the laws of literature itself. According to SHEN Cong-wen, a writer was evaluated by his or her literary works, so the writer should take literature as religion, be a willing martyr of literature and never hold a playing or fad attitude towards literature.

What we should do now is to persuade writers not to play literature. We should pay much attention to any positive attitude opposite to the "playing attitude towards literature". Literary utilitarianism has become a diction which can degrade literature to a vulgar thing. Nevertheless, if the utilitarianism can change our weakness into health, the bad into the good as well as the unbeautiful into the beautiful, it still has its advantages. (SHEN, 2002k, p. 40)

It may seem contradictory that SHEN Cong-wen advocated literary super-utility view on the one hand and stressed literary utilitarianism on the other hand. In fact, this is out of his Chinese-style "misunderstanding” and transformation of Western aesthetic modernity. It is notable that "literary utilitarianism” proposed by SHEN Cong-wen is obviously different from left-wing literature which is intertwined with politics and Shanghai-school literature which has a collusive relation with business. It is also different from Western aesthetic modernity which simply takes aesthetics as its representation. It is essentially a kind of aesthetic utilitarianism interweaving aesthetic independence with mind enlightenment, and it is an ideology of aesthetic modernity with distinct Chinese characteristics.

To SHEN Cong-wen (2002l), literature should be given the historical mission of reconstructing tools:

The society must be reconstructed, which should start with reconstructing literature. After the literary revolution, literature can be used to evoke the whole nation's emotions which were restrained by power and to stimulate the whole nation's reason which was shriveled and distorted by fortune. Both emotion and reason must be emancipated, and new literature must take many responsibilities for the emancipation of emotion and reason. (p. 375)

In his article "Contributions of People in Western Hunan to New Literature Movement” (2002m), SHEN Cong-wen directly equated "new literature movement” to "tool-reconstructing and tool-reusing movement”. To him, major problems of China lies in poverty, foolishness, and selfishness:

There are solutions to the problem of poverty in material, so it is easy to solve. However, the problem of foolishness should be solved through planting new educational ideas into the mind of some conscientious people. In each educational 
phase from elementary school to college, educators should pay attention to how to cultivate people's emotions, evoke their emotions, broaden their emotions and explore their emotions. (SHEN, 2002n, p. 392)

Literature is just the best carrier for the religion of beauty and love. To him, a good literary work should not only provide people with a sense of truth and beauty but also possess a force leading people to a tendency towards kindness. He believed that "beauty is a form of kindness, and the progress of a culture is just a symbol of pursuing kindness or beauty" (SHEN, 2002o, p. 343). Anyway, the aesthetic utilitarianism advocated by SHEN Cong-wen is different from the absolute aestheticism and the absolute moralism, for it centered on combining aesthetics with life and it is an art for life. Moreover, its ultimate orientation lies in the understanding of life, in other words, life is provided with divine ideology.

\section{Conclusion}

SHEN Cong-wen had always spiritual beliefs in advocating divinity. He thought that the divine spirit had the power to prevent human spirits from being degraded in the age lacking values and beliefs. Human beings are able to "recreate divinity and use the abstract divinity to prevent the degradation from being expanded and then to provide the new life with stimulation and enlightenment” (SHEN, 2002p, p. 362). He dealt with the difficult situation where human nature and beliefs lose due to enlightening modernity by providing the divine ideology with the function of redemption. In the modernity context where divinity and enchantment are abandoned, SHEN Cong-wen's divine ideology is of the significant meaning of aesthetic redemption.

However, the orientation of aesthetic redemption is not limited to this point. SHEN Cong-wen deemed that "the understanding of life enables one to make out how human's divine characters are related with human's evil characters in a negative way, to understand various life forms, and to consider other things beyond personal life experiences" (SHEN, 2002q, p. 494). Moreover, he held that the ultimate orientation of understanding of life lies in integrating vitality of individuals into efforts of the whole nation in making progress. In this way, aesthetic redemption has the meaning of mind enlightenment with Chinese characteristics.

Indeed, just as LIU Xiao-feng (1998) pointed it out, there is "no Chinese modernity which is absolutely different from European and American modernity, although Chinese modernity is of concrete historical characteristics", and so it is "worth trying to look into the problems of Western countries while investigating the problems of China and thereafter return to the problems of China" (p. 3). Therefore, it is particularly necessary for us to examine SHEN Cong-wen's aesthetic modernity from the "double perspectives" of both the Chinese and the Western perspectives.

\section{References}

KONG, F. J. (2003). The modern transformation of Chinese literatures and the reconstruction of history of literatures. Literary Review, 8(4).

LIU, X. F. (1998). Introduction of social theories of modernity. Shanghai: SDX Joint Publishing Company.

QIAN, L. Q. (2001). History, philosophy and psychology in The New and The Old. In C. W. SHEN (Ed.), Appreciation of SHEN Cong-wen's masterpieces. Beijing: China Peace Publishing House.

Schiller, J. C. F. (1984). On the aesthetic education of man (H. C. XU, Trans.). Beijing: The Publishing House of China Federation of Literary and Art Circles.

SHEN, C. W. (2002a). After raining. In Complete works of SHEN Cong-wen (Vol. 3). Taiyuan: Beiyue Literature \& Arts Publishing House. 
SHEN, C. W. (2002b). Preface of The Long River. In Complete works of SHEN Cong-wen (Vol. 10). Taiyuan: Beiyue Literature \& Arts Publishing House.

SHEN, C. W. (2002c). Story on January 18th of 1934. In Complete works of SHEN Cong-wen (Vol. 11). Taiyuan: Beiyue Literature \& Arts Publishing House.

SHEN, C. W. (2002d). My studies. In Complete works of SHEN Cong-wen (Vol. 12). Taiyuan: Beiyue Literature \& Arts Publishing House.

SHEN, C. W. (2002e). The intellectual class and progress. In Complete works of SHEN Cong-wen (Vol. 14). Taiyuan: Beiyue Literature \& Arts Publishing House.

SHEN, C. W. (2002f). The story of meeting again the Barbaric man. In Complete works of SHEN Cong-wen (Vol. 11). Taiyuan: Beiyue Literature \& Arts Publishing House.

SHEN, C. W. (2002g). Cedar Seed. In Complete works of SHEN Cong-wen (Vol. 9). Taiyuan: Beiyue Literature \& Arts Publishing House.

SHEN, C. W. (2002h). Xiaoxiao. In Complete works of SHEN Cong-wen (Vol. 8). Taiyuan: Beiyue Literature \& Arts Publishing House.

SHEN, C. W. (2002i). Afterword of Foam of Life. In Complete works of SHEN Cong-wen (Vol. 16). Taiyuan: Beiyue Literature \& Arts Publishing House.

SHEN, C. W. (2002j). Reconstruction of literary movement. In Complete works of SHEN Cong-wen (Vol. 17). Taiyuan: Beiyue Literature \& Arts Publishing House.

SHEN, C. W. (2002k). Chat in the narrow and moldy room. In Complete works of SHEN Cong-wen (Vol. 17). Taiyuan: Beiyue Literature \& Arts Publishing House.

SHEN, C. W. (2002l). Learning from reality. In Complete works of SHEN Cong-wen (Vol. 17). Taiyuan: Beiyue Literature \& Arts Publishing House.

SHEN, C. W. (2002m). Contributions of people in Hunan to new literature movement. In Complete works of SHEN Cong-wen (Vol. 17). Taiyuan: Beiyue Literature \& Arts Publishing House.

SHEN, C. W. (2002n). Poverty and foolish. In Complete works of SHEN Cong- wen (Vol. 12). Changsha: Hunan People's Publishing House.

SHEN, C. W. (20020). Afterword of Records of Seeing Rainbows and Picking Stars. In Complete works of SHEN Cong-wen (Vol. 16). Taiyuan: Beiyue Literature \& Arts Publishing House.

SHEN, C. W. (2002p). Beauty and love. In Complete works of SHEN Cong-wen (Vol. 17). Taiyuan: Beiyue Literature \& Arts Publishing House.

SHEN, C. W. (2002q). Short stories. In Complete works of SHEN Cong-wen (Vol. 16). Taiyuan: Beiyue Literature \& Arts Publishing House.

WANG, H., CHEN, P. Y., \& WANG, S. C. (1994). Weber and issues about Chinese modernity. In The scholar (Vol. 6). Nanjing: Jiangsu People's Publishing Ltd..

WEN, F. Q. (2004). Introduction. In F. Q. WEN (Ed.), Modernity and Chinese literature in the 20th century. Qingdao: China Ocean University Press. 